\title{
BMJ Loss of epithelial membrane protein-2 open expression confers an independent prognosticator in nasopharyngeal carcinoma: a cohort study
}

\author{
Yi-Hsien Chen, ${ }^{1}$ Li-Ching Wu, ${ }^{2}$ Wen-Ren Wu, ${ }^{3}$ Hung-Jung Lin, ${ }^{1}$ Sung-Wei Lee, ${ }^{4}$ \\ Ching-Yih Lin, ${ }^{5}$ Shih-Lun Chang, ${ }^{6}$ Nan-Haw Chow, ${ }^{7,8}$ Hsuan-Ying Huang, ${ }^{9}$ \\ Chien-Feng $\mathrm{Li}^{2,3,10,11}$ Han-Ping Hsu, ${ }^{12}$ Yow-Ling Shiue ${ }^{3}$
}

To cite: Chen Y-H, Wu L-C, Wu W-R, et al. Loss of epithelial membrane protein-2 expression confers an independent prognosticator in nasopharyngeal carcinoma: a cohort study. BMJ Open 2012;2:e000900. doi:10.1136/ bmjopen-2012-000900

- Prepublication history for this paper is available online. To view these files please visit the journal online (http:// dx.doi.org/10.1136/ bmjopen-2012-000900).

Received 21 January 2012 Accepted 27 February 2012

This final article is available for use under the terms of the Creative Commons Attribution Non-Commercial 2.0 Licence; see http://bmjopen.bmj.com

For numbered affiliations see end of article.

Correspondence to Professor Yow-Ling Shiue; ylshiue@mail.nsysu.edu.tw

\section{ABSTRACT}

Objective: To evaluate the expression of epithelial membrane protein-2 (EMP2) protein and its clinicopathological associations in patients with nasopharyngeal carcinoma.

Design: Retrospective population-based cohort study. Setting: This study was based on a biobank in Chi-Mei Medical Center (Tainan, Taiwan) from 1993 to 2002.

Participants: Biopsies of 124 consecutive nasopharyngeal carcinoma patients without initial distant metastasis and treated with consistent guidelines were assessed. Immunoexpressions of EMP2 were analysed and the outcomes were correlated with clinicopathological features and patient survivals.

\section{Primary and secondary outcome}

measures: Immunoexpressions of EMP2 were analyzed and the outcomes were correlated with clinicopathological features and patient survivals.

Results: Loss of EMP2 expression (49.2\%) was correlated with advanced primary tumour $(p=0.044)$, nodal status $(p=0.045)$ and the 7 th American Joint Committee on Cancer stage $(p=0.027)$. In multivariate analyses, loss of EMP2 expression emerged as an independent prognosticator for worse disease-specific survival (DSS; $p=0.015$ ) and local recurrence-free survival (LRFS; $p=0.030$ ), along with the American Joint Committee on Cancer stages III-IV ( $p=0.034$, DSS; $p=0.023$, LRFS).

Conclusions: Loss of EMP2 expression is common and associated with adverse prognosticators and might confer tumour aggressiveness through hampering its interaction with specific membrane protein(s) and hence the downstream signal transduction pathway(s).

\section{INTRODUCTION}

Nasopharyngeal carcinoma (NPC) is an endemic head and neck epithelial malignancy in Southeastern Asia and Taiwan, strongly linked to Epstein-Barr virus (EBV). ${ }^{1-3}$ The latter association is especially authentic for the differentiated and undifferentiated

\section{ARTICLE SUMMARY}

Article focus

- Recent studies have suggested that EMP2 plays a tumour suppressor role in B cell lymphomas.

- Immunoexpression of EMP2 was retrospectively assessed in biopsies of 124 consecutive patients with nasopharyngeal carcinoma.

\section{Key messages}

- Loss of EMP2 expression significantly correlates with advanced primary tumour, nodal status and AJCC stage.

- In multivariate analyses, loss of EMP2 expression emerges as an independent prognosticator for worse disease-specific survival and local recurrence-free survival.

Strengths and limitations of this study

- Significant correlation between loss of EMP2 expression and several clinicopathologic variables supported its potential role in nasopharyngeal carcinomas.

- The molecular mechanisms underlying EMP2 action require to be elucidated.

non-keratinising carcinoma types, according to current WHO tumour classification, although genetic and environmental factors also play certain roles in pathogenesis. ${ }^{124}$ The advances in diagnostic imaging, radiation therapy and adjuvant chemotherapy of NPC have achieved better locoregional control, while it appears less satisfactory in final treatment outcomes. ${ }^{5}{ }^{6}$ Even though being an important parameter, Tumour, Node, Metastasis staging still has space to improve in terms of providing the optimal prognostication to the patients. ${ }^{1} 5$ 7 Therefore, to identify potential biomarkers with better correlation to tumour growth and/or treatment outcomes in patients with NPC, subsequently, to aid in risk stratification and perhaps development of therapeutic targets, are indispensable. 
Human epithelial membrane protein-2 gene (EMP2), mapped to chromosome 16 , is highly conserved across vertebrates. ${ }^{8-10}$ The expression pattern of EMP2 partially overlaps to that of the peripheral myelin protein 22 (PMP22, also known as the growth arrest-specific-3, GAS3) transcript. By containing the claudin domain and sharing approximately $40 \%$ amino acid identity with PMP22/GAS3, ${ }^{11}$ the EMP2 protein was detected as a novel member of this four-transmembrane (tetraspan) superfamily. ${ }^{12}$ In humans, EMP2 has a discrete cell type and tissue distribution, with high levels observed in the lung and moderate levels in the eye, heart, thyroid, uterus and intestine. ${ }^{11} 13 \quad 14$ Functionally, the best understood tetraspan proteins are connexins, which form the major structural element of gap junctions. Connexins play important roles in the regulation of cell growth and differentiation. Cancer cells usually have downregulated levels of gap junctions, and several lines of evidence suggest that loss of gap junctional intercellular communication is an important step in carcinogenesis. Re-expression of connexins in cancer cells causes normalisation of cell growth control and reduced tumour growth. ${ }^{15}$ Accordingly, we aimed to systematically analyse EMP2 immunoexpression in patients with NPC and identified that loss of EMP2 expression is associated with adverse prognosticators, conferring to poor survivals.

\section{MATERIALS AND METHODS}

\section{Patients and tumour specimens}

The institutional review board approved the study by using formalin-fixed tissue of NPC for this study (IRB100-09-003). Available paraffin-embedded tissue blocks were retrieved from 124 NPC patients who underwent biopsy between January 1993 and December 2002. These patients were free of distant metastasis at initial presentation. The histological subtypes were reappraised according to the current WHO classification and, the tumour staging was re-evaluated with the 7th American Joint Committee on Cancer (AJCC) system by two pathologists, independently.

\section{Immunohistochemical staining and assessment of EMP2 expression}

Tissue sections of $3 \mu \mathrm{m}$ thickness were cut onto precoated slides from paraffin-embedded tissue blocks and were next routinely deparaffinized with xylene and rehydrated with ethanol washes. Slides were heated by the microwave in a $10 \mathrm{mM}$ citrate buffer $(\mathrm{pH}$ 6.0) for $7 \mathrm{~min}$ to retrieve antigens. Endogenous peroxidase was blocked with $3 \% \mathrm{H}_{2} \mathrm{O}_{2}$. Slides were next washed by Trisbuffered saline for $15 \mathrm{~min}$ and subsequently incubated with a rabbit polyclonal primary antibody targeting EMP2 (Atlas Antibodies, Stockholm, Sweden) at a dilution of 1:75 for $1 \mathrm{~h}$. Primary antibodies were detected using the DAKO ChemMate EnVision Kit (K5001, Carpinteria, California, USA). The slides were incubated and developed with the secondary antibody for $30 \mathrm{~min}$ and 3,3-diaminobenzidine for $5 \mathrm{~min}$, followed by counterstained using Gill's haematoxylin. Immunoexpression of EMP2 was scored by two pathologists (C-FL and $\mathrm{H}-\mathrm{YH}$ ) using a multiheaded microscope to reach a consensus for each case without prior knowledge of clinical and follow-up information. The percentage of tumour cells with EMP2 immunoexpression was recorded for each specimen and loss of EMP2 expression (negative) was defined in cases with staining $\leq 5 \%$ tumour cells (see the Statistical analysis section).

\section{Treatment and follow-up}

All 124 patients with follow-up for outcome have received complete course of radiotherapy (RT, total dose $\geq 7000 \mathrm{cGy}$ ) and also cisplatin-based chemotherapy in those of stage II-IV diseases, based on the previously published protocol. ${ }^{16}$ The method of RT was in general uniform within this period. All patients were regularly monitored after RT until death or their last appointment with the mean follow-up duration being 59.6 months (range: 4-117).

\section{Statistical analysis}

Statistics were performed using SPSS V.14.0 software (SPSS Inc). $\chi^{2}$ Test was used to compare the EMP2 expression status and various clinicopathological parameters. The end points analysed were diseasespecific survival (DSS) and local recurrence-free survival (LRFS), calculated from the starting date of RT to the

\begin{tabular}{lc}
$\begin{array}{l}\text { Table } 1 \text { Clinical pathological features of } 124 \\
\text { nasopharyngeal carcinomas }\end{array}$ \\
\hline Variable & $\mathbf{n}(\%)$ \\
\hline Gender & \\
Male & $95(76.6)$ \\
Female & $29(23.4)$ \\
Age (years) & \\
$\quad<60$ & $98(79.0)$ \\
$\geq 60$ & $26(21.0)$ \\
Primary tumour (T) & \\
T1 & $30(24.2)$ \\
T2 & $50(40.3)$ \\
T3 & $21(16.9)$ \\
T4 & $23(18.5)$ \\
Nodal status (N) & \\
N0 & $24(19.4)$ \\
N1 & $32(25.8)$ \\
N2 & $48(38.7)$ \\
N3 & $20(16.1)$ \\
Stage & $7(5.6)$ \\
I & $31(25.0)$ \\
II & $46(37.1)$ \\
III & $40(32.2)$ \\
IV & \\
Histological grade & $5(4.0)$ \\
Keratinising & $54(43.5)$ \\
Non-keratinising/differentiated & $65(52.4)$ \\
Non-keratinising/undifferentiated & \\
EMP2 expression level & $63(50.8)$ \\
Positive $(>5 \%$ tumour cells) & $61(49.2)$ \\
Negative ( 5 5 tumour cells)
\end{tabular}


Figure 1 Immunohistochemically non-tumour respiratory epithelium (A) and those with squamous metaplasia (B) demonstrate diffuse and strong EMP2 immunoexpression, which can also be appreciated in representative non-keratinising carcinoma $(C)$ but not in undifferentiated one (D).
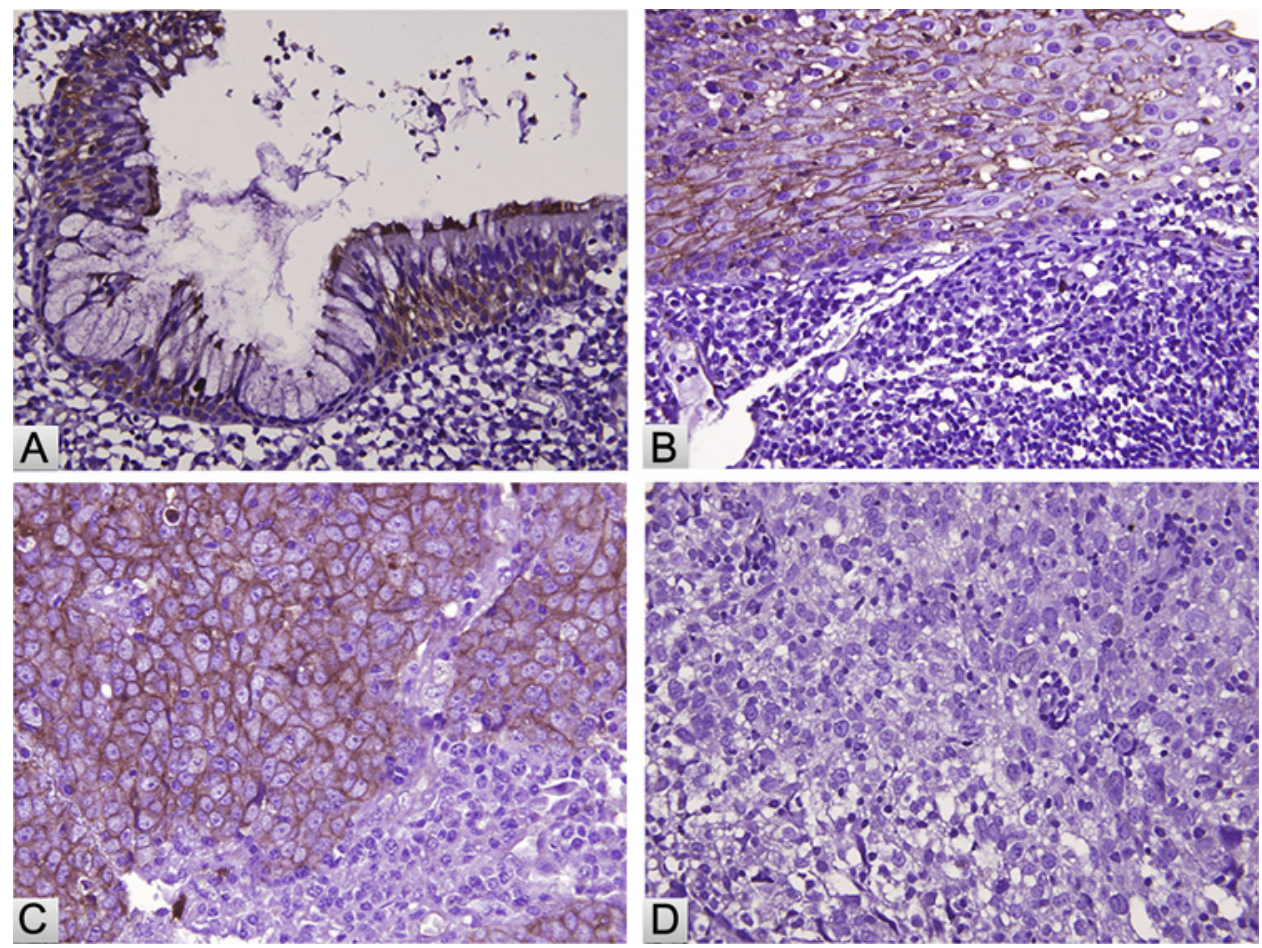

date of event developed. Patients lost to follow-up were censored on the latest follow-up date. Survival curves were plotted using the Kaplan-Meier method, and the log-rank test was performed to evaluate prognostic differences between groups. Multivariate analysis was carried out by the Cox proportional hazards model. However, as a component factor of the AJCG stage, primary tumour $(\mathrm{T})$ and nodal status $(\mathrm{N})$ was not introduced in multivariate comparisons. After testing a series of cut-off values in 5\% increment, EMP2 expression was construed as negative when the expression index was $\leq 5 \%$ tumour cells. For all analyses, twosided tests of significance were used with $\mathrm{p}<0.05$ considered significant.

\section{RESULTS}

Immunohistochemical expression of EMP2 and associations with clinicopathological variables in NPC specimens

As shown in table 1, 124 cases of NPC consisted of five keratinising squamous cell carcinomas, 54 non-keratinising differentiated carcinomas and 65 non-keratinising undifferentiated carcinomas. A total of 95 men and 29 women with a mean age of 48.6 years (range, 20-83) were included. Seven cases were classified as stage I, 31 as stage II, 46 as stage III and 40 as stage IV. Immunoexpression of EMP2 was observed and successfully scored in all cases. Tumour-adjacent normal respiratory epithelium (figure 1A) or non-tumour epithelium with squamous metaplasia (figure 1B) could be appreciated in 71 samples and all showed intense EMP2 immunoexpression. A wide range of stained tumour cell, characterised by cytoplasmic and/or membranous staining, varying from $0 \%$ to $90 \%$ (median, 30\%) were detected in tumour elements. Of these, 63 cases showed characteristic EMP2 staining ( $>5 \%$ tumour cells; figure 1C), while 61 cases were $<5 \%$ staining and therefore classified as EMP2 negative (figure 1D). Loss of EMP2 expression was significantly associated with cases featuring increment of primary tumour $(p=0.004)$, nodal status $(p=0.045)$ and AJCC stage $(p=0.027)$ (table 2). However, no significant association between the EMP2 expression level and other clinicopathological factor was found.

\section{Prognostic impact of EMP2 expression in NPC}

Patients with NPC more frequently progressed to disease-specific mortality with N2-N3 nodal status $(p=0.002)$ and stages III-IV $(p=0.007) \quad($ table 3). Besides, patients with advanced AJCC stages III-IV held shorter DSS $(p=0.07$; figure $2 A)$ and LRFS $(p=0.06$; figure 2B). The development of local recurrence was significantly associated with $\mathrm{T} 3-\mathrm{T} 4(\mathrm{p}=0.027)$, N2-N3 status $(p=0.023)$ and AJCC stages III-IV $(p=0.005)$ with a medium duration of 24 months (table 3). Of note, EMP2 negative correlated to a more aggressive clinical course with a significantly shorter DSS $(p=0.002$; figure 2C) and LRFS ( $p=0.005$; figure 2D) in patients with NPC. In multivariate analysis (table 4), loss of EMP2 expression steady remained as a robust prognosticator for both inferior DSS $(\mathrm{p}=0.015, \mathrm{HR}=1.969)$ and worse LRFS $(p=0.030, H R=2.136)$, following tumour stage $(\mathrm{p}=0.034, \mathrm{HR}=2.115 ; \mathrm{p}=0.023, \mathrm{HR}=3.046$, for $\mathrm{DSS}$ and LRFS, respectively).

\section{DISCUSSION}

Loss of EMP2 immunostaining as one potent prognosticator for both DSS and LRFS in a subset of patients with NPG was sustained in this study. Intriguingly, we 
Table 2 Expression level of EMP2 and correlations with clinicopathologic variables $(n=124)$

\begin{tabular}{|c|c|c|c|}
\hline \multirow[b]{2}{*}{ Variable } & \multicolumn{2}{|c|}{ EMP2 expression score } & \multirow[b]{2}{*}{ p Value } \\
\hline & $\begin{array}{l}\text { Positive (>5\% } \\
\text { tumour cells) }\end{array}$ & $\begin{array}{l}\text { Negative ( } \leq 5 \% \\
\text { tumour cells) }\end{array}$ & \\
\hline Gender & & & 0.926 \\
\hline Male & 43 & 52 & \\
\hline Female & 20 & 9 & \\
\hline Age (years) & & & 0.926 \\
\hline$<60$ & 50 & 48 & \\
\hline$\geq 60$ & 13 & 13 & \\
\hline Primary tumour $(\mathrm{T})$ & & & $0.044^{*}$ \\
\hline $\mathrm{T} 1-\mathrm{T} 2$ & 46 & 34 & \\
\hline T3-T4 & 17 & 27 & \\
\hline Nodal status (N) & & & $0.045^{*}$ \\
\hline $\mathrm{N} 0-\mathrm{N} 1$ & 34 & 22 & \\
\hline N2-N3 & 29 & 39 & \\
\hline Stage & & & $0.027^{*}$ \\
\hline I-II & 25 & 13 & \\
\hline III-IV & 38 & 48 & \\
\hline Histological grade & & & 0.879 \\
\hline Keratinising & 3 & 2 & \\
\hline Non-keratinising/differentiated & 28 & 26 & \\
\hline Non-keratinising/undifferentiated & 32 & 33 & \\
\hline
\end{tabular}

have also identified a significant association between loss of EMP2 expression and the overexpression of latent membrane protein $1 \quad(p=0.007$, data not shown $)$, an important oncoprotein of $\mathrm{EBV},{ }^{17}$ suggesting a potential role of EMP2 loss in EBV-associated tumour progression.
However, significantly high EMP2 expression was found in ovarian cancer through activation of caveolins/glycosylphosphatidyl inositol-linked proteins ${ }^{18}$ and was identified as an early predictor of endometrial cancers with unfavourable outcome. ${ }^{19}$ Due to non-neoplastic

\begin{tabular}{|c|c|c|c|c|c|}
\hline \multirow[b]{2}{*}{ Variable } & \multirow[b]{2}{*}{$\mathbf{n}$} & \multicolumn{2}{|c|}{ DSS } & \multicolumn{2}{|c|}{ LRFS } \\
\hline & & $\mathbf{n}$ & p Value & $\mathbf{n}$ & p Value \\
\hline Gender & & & 0.878 & & 0.346 \\
\hline Male & 95 & 45 & & 30 & \\
\hline Female & 29 & 14 & & 7 & \\
\hline Age (years) & & & 0.996 & & 0.755 \\
\hline$<60$ & 98 & 48 & & 29 & \\
\hline$\geq 60$ & 26 & 11 & & 8 & \\
\hline Primary tumour $(\mathrm{T})$ & & & 0.065 & & $0.027^{\star}$ \\
\hline $\mathrm{T} 1-\mathrm{T} 2$ & 80 & 32 & & 19 & \\
\hline T3-T4 & 44 & 27 & & 18 & \\
\hline Nodal status (N) & & & $0.002^{*}$ & & $0.023^{*}$ \\
\hline $\mathrm{N} 0-\mathrm{N} 1$ & 56 & 18 & & 12 & \\
\hline N2-N3 & 68 & 41 & & 25 & \\
\hline Stage & & & $0.007^{\star}$ & & $0.005^{\star}$ \\
\hline$|-| \mid$ & 38 & 10 & & 3 & \\
\hline III-IV & 86 & 49 & & 32 & \\
\hline Histological grade & & & 0.157 & & 0.900 \\
\hline Keratinising/non-keratinising & 47 & 40 & & 15 & \\
\hline Undifferentiated & 77 & 39 & & 22 & \\
\hline EMP2 expression level & & & $0.002^{*}$ & & $0.005^{\star}$ \\
\hline Positive ( $>5 \%$ tumour cells) & 63 & 21 & & 13 & \\
\hline Negative ( $\leq 5 \%$ tumour cells) & 61 & 38 & & 24 & \\
\hline
\end{tabular}


Figure 2 Kaplan-Meier plotting illustrates the prognostic significance of tumour stage for (A) disease-specific survival (DSS) and (B) local recurrencefree survival (LRFS), respectively. The predictive value of EMP2 expression is also demonstrated (C, D).
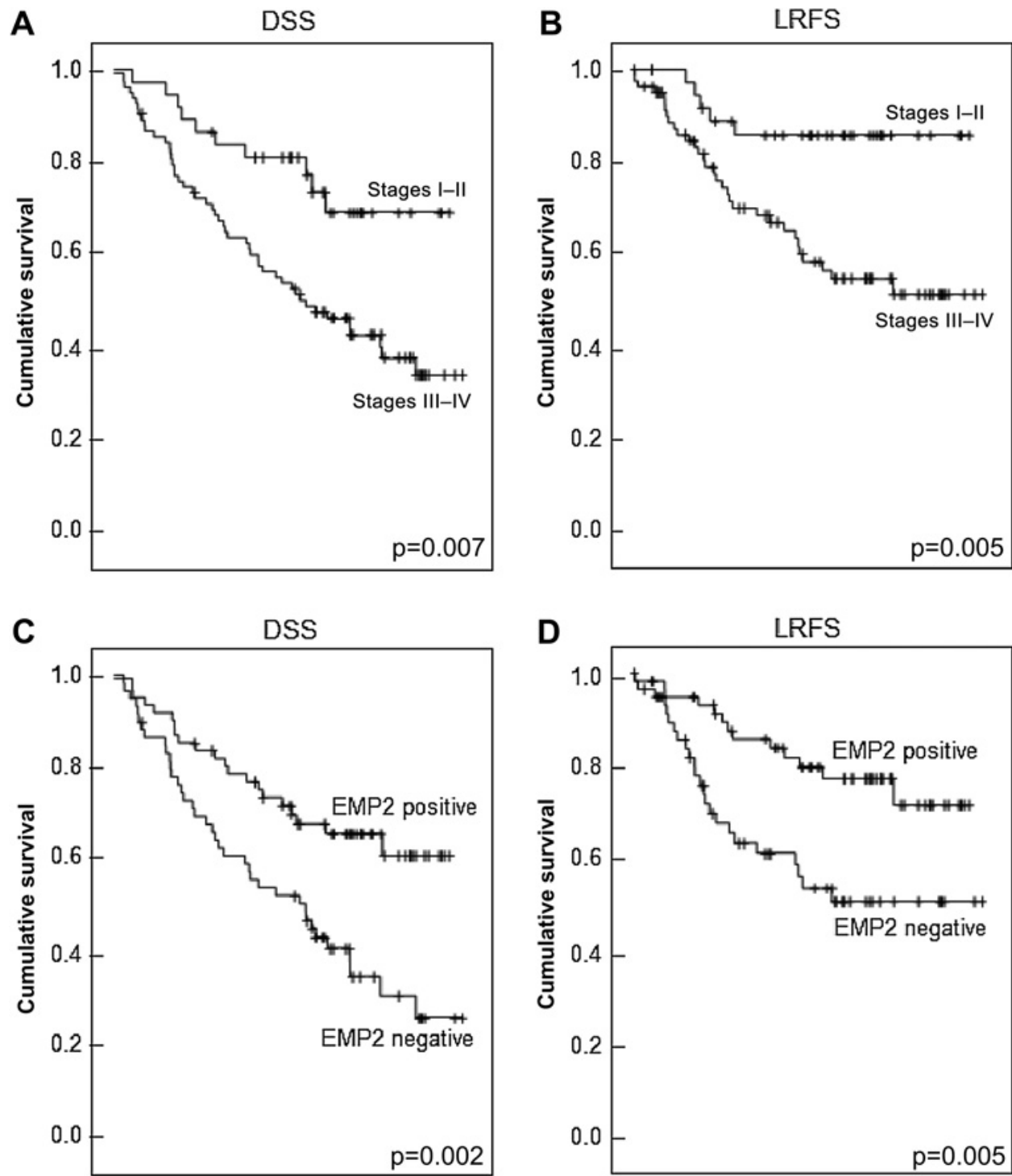

peritoneal, surface tissues were complete negative for EMP2 staining, thus EMP2 was regarded as increased expression in tumour cells in ovarian cancer. ${ }^{20}$ Moderately intense diffuse immunohistochemical stainings of tumour cell cytoplasm were identified in endometrioid adenocarcinoma, serous carcinoma, mixed endometrioid and serous carcinoma, mixed endometrioid and clear cell carcinoma. ${ }^{21}$ On the other hand, compared with undifferentiated ones, predominant expressions of EMP2 in cytoplasm and/or membrane of squamous metaplasias and non-keratinising NPCs were found in our study, suggesting that loss of EMP2 expression might change its interactions with some membrane proteins in NPC. Surface expression of the $\alpha 6 \beta 1$ integrin was specifically increased by EMP2 in NIH3T3 fibroblasts. ${ }^{22}$ Moreover, surface expression and trafficking of integrin

Table 4 Multivariate survival analysis of EMP2 expression level on survival outcome

\begin{tabular}{|c|c|c|c|c|}
\hline \multirow[b]{2}{*}{ Variable } & \multicolumn{2}{|l|}{ DSS } & \multicolumn{2}{|l|}{ LRFS } \\
\hline & HR (95\% Cl) & p Value & HR (95\% Cl) & p Value \\
\hline AJCC stage & & $0.034^{*}$ & & $0.023^{*}$ \\
\hline $\mathrm{I}-\mathrm{II}$ & 1 & & 1 & \\
\hline III-IV & 2.115 (1.057 to 4.232$)$ & & 3.046 (1.171 to 7.919$)$ & \\
\hline EMP2 expression level & & $0.015^{\star}$ & & $0.030^{\star}$ \\
\hline Positive ( $>5 \%$ tumour cells) & 1 & & 1 & \\
\hline Negative ( $\leq 5 \%$ tumour cells) & 1.969 (1.144 to 3.391$)$ & & 2.136 (1.076 to 4.237$)$ & \\
\hline
\end{tabular}


$\alpha_{\mathrm{v}} \beta 3$ during the window of implantation, which are essential for endometrial-blastocyst interaction in mice, were affected by the EMP2 level and the association between EMP2 and focal adhesion kinase. ${ }^{19} 2324$ In mammals, $18 \alpha$ and eight $\beta$ subunits assemble into 24 different integrins, which bind collagens, laminins or arginine-glycine-aspartic acid-containing proteins. Integrins are regulated by conformational changes, clustering and trafficking, and regulatory mechanisms differ strongly between individual integrins and between cell types. Defective integrin activation or integrin signalling is associated with an array of pathological conditions. ${ }^{25}$ Endocytosis and recycling are crucial in the regulation of integrin turnover and redistribution in adherent cells, especially during dynamic processes such as migration and invasion. ${ }^{26}$ Therefore, EMP2 probably plays a tumour suppressor role through interacting with specific integrin(s) in epithelial cells and, thereafter, manages regular signalling transduction in benign conditions.

In addition to the above finding, we uncovered that ectopic expression of EMP2 in a malignant human urothelial cell line, J82, significantly reduced cell proliferation, cell cycle progression, migration and invasion in vitro (unpublished). Consistently, suppression subtractive hybridisation technologies isolated mouse orthologue Emp2, which suppresses B cell lymphoma tumorigenicity through a functional tumour suppressor phenotype. ${ }^{10}$

The susceptibility to allogeneic cytotoxic $\mathrm{T}$ lymphocytes of a mouse malignant, Emp2-deficient cell line $(\mathrm{MV})^{10}$ has been enhanced by retroviral overexpression of Emp2 gene. ${ }^{27}$ Constitutive overexpression of EMP2 or other epithelial membrane proteins including EMP1, EMP3 and PMP22, in human HEK293 epithelial cells, leading to the development of apoptotic phenotypes, were demonstrated by purinergic receptor P2X, ligandgated ion channel, 7 (P2RX7)-mediated cell blebbing, annexin $\mathrm{V}$ binding to plasma membrane and cell death, through a caspase-dependent pathway. Physically, the C-terminal domain of P2RX7 protein associates with EMPs and mediates some aspects of the downstream signalling following P2RX7 activation. ${ }^{28}$ All these studies supported our clinical observations, reinforcing that EMP2 might play distinct characteristics in different cellular contexts. Indeed, the aetiology of NPC is complex, including a host of viral, genetic and environmental factors. ${ }^{329}{ }^{30}$ In spite of cure for the majority of the patients, challenges still exist in the prevention of disease relapse and treatment of patients with refractory or metastatic NPC. ${ }^{31-33}$ Therefore, for the first time, loss of EMP2 expression was identified as a biomarker independently correlated with tumour aggression to facilitate appropriate allocation of adjuvant therapy, suggesting its significance for patient-tailored strategy to manage high-risk NPCs.

Except for loss of EMP2 expression, significantly increased HRs of DSS and LRFS in NPC patients with higher stages (III-IV) were further ascertained, analogous to other studies. ${ }^{34-36}$ Additionally, we revealed significant correlations between loss of EMP2 expression and primary tumour, nodal status and stage in NPCs, indicating its prospective role in preventing NPC progression and aggressiveness. Although the precise characteristics of the EMP2 protein in NPC progression remain to be elucidated, the potential utility of EMP2 immunostaining as a prognostic biomarker in NPCs is assured.

\section{Author affiliations}

${ }^{1}$ Department of Emergency Medicine, Chi-Mei Medical Center, Tainan, Taiwan 2Department of Pathology, Chi-Mei Medical Center, Tainan, Taiwan

${ }^{3}$ Institute of Biomedical Science, National Sun Yat-sen University, Kaohsiung, Taiwan

${ }^{4}$ Department of Radiation Oncology, Chi-Mei Medical Center, Liouying, Tainan, Taiwan

${ }^{5}$ Division of Gastroenterology and Hepatology, Department of Internal Medicine, Chi-Mei Medical Center, Tainan, Taiwan

${ }^{6}$ Department of Otolaryngology, Chi-Mei Medical Center, Tainan, Taiwan ${ }^{7}$ Department of Pathology, National Cheng Kung University Hospital, Tainan, Taiwan

${ }^{8}$ Institute of Basic Medical Sciences, National Cheng Kung University, Tainan, Taiwan

${ }^{9}$ Department of Pathology, Chang Gung Memorial Hospital-Kaohsiung Medical Center, College of Medicine, Chang Gung University, Kaohsiung, Taiwan

${ }^{10}$ National Institute of Cancer Research, National Health Heath Research Institute, Tainan, Taiwan

${ }^{11}$ Department of Biotechnology, Southern Taiwan University, Tainan, Taiwan

${ }^{12}$ College of Medicine, China Medical University, Taichung, Taiwan

Contributors Y-HC, L-CW, W-RW, H-JL, S-WL, C-YL, S-LC, N-HC, H-YH, C-FL, $\mathrm{H}-\mathrm{PH}$ and $\mathrm{Y}-\mathrm{LS}$ participated in the conception and design, acquisition, analysis and interpretation of data. C-FL and Y-LS drafted the article and all authors revised it critically for important intellectual content. All authors gave final approval of the version to be published.

Funding This work was supported by grants DOH99-TD-C-111-004 (Department of Health, Taiwan) to C-FL for tissue dissection and immunohistochemical analysis; CMFHR10119 (Chi-Mei Medical Center) to L-CW for case history analysis; 98-2311-B-110-001-MY3 (National Science Council, Taiwan) to Y-LS for target (EMP2) prioritisation.

Competing interests None.

Ethics approval Ethics approval was provide by the institutional review board (IRB100-09-003).

Provenance and peer review Not commissioned; externally peer reviewed.

Data sharing statement The original immunostaining and statistical data are available from the corresponding author at ylshiue@mail.nsysu.edu.tw.

\section{REFERENCES}

1. Chang ET, Adami HO. The enigmatic epidemiology of nasopharyngeal carcinoma. Cancer Epidemiol Biomarkers Prev 2006;15:1765-77.

2. Yu MC, Yuan JM. Epidemiology of nasopharyngeal carcinoma. Semin Cancer Biol 2002;12:421-9.

3. Liebowitz D. Nasopharyngeal carcinoma: the Epstein-Barr virus association. Semin Oncol 1994;21:376-81.

4. Lo KW, To KF, Huang DP. Focus on nasopharyngeal carcinoma. Cancer Cell 2004;5:423-8.

5. Fang FM, Chien CY, Li CF, et al. Effect of S-phase kinase-associated protein 2 expression on distant metastasis and survival in nasopharyngeal carcinoma patients. Int J Radiat Oncol Biol Phys 2009;73:202-7

6. Fang FM, Tsai WL, Go SF, et al. Implications of quantitative tumor and nodal regression rates for nasopharyngeal carcinomas after 45 Gy of radiotherapy. Int J Radiat Oncol Biol Phys 2001;50:961-9. 
7. Jeyakumar A, Brickman TM, Doerr T. Review of nasopharyngeal carcinoma. Ear Nose Throat $J$ 2006;85:168-70, 172-3, 184.

8. Ben-Porath I, Kozak CA, Benvenisty N. Chromosomal mapping of Tmp (Emp1), Xmp (Emp2), and Ymp (Emp3), genes encoding membrane proteins related to Pmp22. Genomics 1998;49:443-7.

9. Liehr $\mathrm{T}$, Kuhlenbaumer $\mathrm{G}$, Wulf $\mathrm{P}$, et al. Regional localization of the human epithelial membrane protein genes 1,2 , and 3 (EMP1, EMP2, EMP3) to 12p12.3, 16p13.2, and 19q13.3. Genomics 1999;58:106-8.

10. Wang CX, Wadehra M, Fisk BC, et al. Epithelial membrane protein 2, a 4-transmembrane protein that suppresses B-cell lymphoma tumorigenicity. Blood 2001;97:3890-5.

11. Taylor V, Suter U. Epithelial membrane protein-2 and epithelial membrane protein-3: two novel members of the peripheral myelin protein 22 gene family. Gene 1996;175:115-20.

12. Berditchevski F, Odintsova E. Characterization of integrin-tetraspanin adhesion complexes: role of tetraspanins in integrin signaling. $J$ Cell Biol 1999;146:477-92.

13. Jetten $A M$, Suter $U$. The peripheral myelin protein 22 and epithelial membrane protein family. Prog Nucleic Acid Res Mol Biol 2000:64:97-129.

14. Wadehra M, Sulur GG, Braun J, et al. Epithelial membrane protein-2 is expressed in discrete anatomical regions of the eye. Exp Mol Pathol 2003;74:106-12.

15. Kandouz M, Batist G. Gap junctions and connexins as therapeutic targets in cancer. Expert Opin Ther Targets 2010;14:681-92.

16. Wolden SL, Zelefsky MJ, Kraus DH, et al. Accelerated concomitant boost radiotherapy and chemotherapy for advanced nasopharyngeal carcinoma. J Clin Oncol 2001;19:1105-10.

17. Horikawa T, Yang J, Kondo S, et al. Twist and epithelialmesenchymal transition are induced by the EBV oncoprotein latent membrane protein 1 and are associated with metastatic nasopharyngeal carcinoma. Cancer Res 2007;67:1970-8.

18. Wadehra M, Goodglick L, Braun J. The tetraspan protein EMP2 modulates the surface expression of caveolins and glycosylphosphatidyl inositol-linked proteins. Mol Biol Cell 2004:15:2073-83.

19. Wadehra M, Natarajan S, Seligson DB, et al. Expression of epithelial membrane protein-2 is associated with endometrial adenocarcinoma of unfavorable outcome. Cancer 2006;107:90-8.

20. Fu M, Maresh EL, Soslow RA, et al. Epithelial membrane protein-2 is a novel therapeutic target in ovarian cancer. Clin Cancer Res 2010;16:3954-63.
21. Habeeb O, Goodglick L, Soslow RA, et al. Epithelial membrane protein-2 expression is an early predictor of endometrial cancer development. Cancer 2010;116:4718-26.

22. Wadehra M, lyer R, Goodglick L, et al. The tetraspan protein epithelial membrane protein-2 interacts with beta1 integrins and regulates adhesion. J Biol Chem 2002;277:41094-100.

23. Wadehra M, Forbes A, Pushkarna N, et al. Epithelial membrane protein-2 regulates surface expression of alphavbeta3 integrin in the endometrium. Dev Biol 2005;287:336-45.

24. Morales SA, Mareninov S, Coulam P, et al. Functional consequences of interactions between FAK and epithelial membrane protein 2 (EMP2). Invest Ophthalmol Vis Sci 2009;50:4949-56.

25. Chigaev A, Sklar LA. Overview: assays for studying integrindependent cell adhesion. Methods Mol Biol 2012;757:3-14.

26. Margadant C, Monsuur HN, Norman JC, et al. Mechanisms of integrin activation and trafficking. Curr Opin Cell Biol 2011;23:607-14.

27. Wadehra M, Su H, Gordon LK, et al. The tetraspan protein EMP2 increases surface expression of class I major histocompatibility complex proteins and susceptibility to CTL-mediated cell death. Clin Immunol 2003;107:129-36.

28. Wilson HL, Wilson SA, Surprenant A, et al. Epithelial membrane proteins induce membrane blebbing and interact with the P2X7 receptor C terminus. J Biol Chem 2002;277:34017-23.

29. Yuan JM, Wang XL, Xiang YB, et al. Preserved foods in relation to risk of nasopharyngeal carcinoma in Shanghai, China. Int $J$ Cancer 2000;85:358-63.

30. Lo KW, Huang DP. Genetic and epigenetic changes in nasopharyngeal carcinoma. Semin Cancer Biol 2002;12:451-62.

31. Razak AR, Siu LL, Liu FF, et al. Nasopharyngeal carcinoma: the next challenges. Eur J Cancer 2010;46:1967-78.

32. Lee AW, Sze WM, Au JS, et al. Treatment results for nasopharyngeal carcinoma in the modern era: the Hong Kong experience. Int $J$ Radiat Oncol Biol Phys 2005;61:1107-16.

33. Guigay J. Advances in nasopharyngeal carcinoma. Curr Opin Oncol 2008;20:264-9.

34. Xu HM, Liang $\mathrm{Y}$, Chen $\mathrm{Q}$, et al. Correlation of Skp2 overexpression to prognosis of patients with nasopharyngeal carcinoma from South China. Chin J Cancer 2011;30:204-12.

35. Cao XJ, Hao JF, Yang $\mathrm{XH}$, et al. Prognostic value of expression of EGFR and nm23 for locoregionally advanced nasopharyngeal carcinoma. Med Oncol 2011;2011:8.

36. Lee AW, Tung SY, Ngan RK, et al. Factors contributing to the efficacy of concurrent-adjuvant chemotherapy for locoregionally advanced nasopharyngeal carcinoma: combined analyses of NPC-9901 and NPC-9902 Trials. Eur J Cancer 2011;47:656-66. 